\title{
Nutrigenetics-Personalized Nutrition in the Genetic Age
}

\author{
Emma L. Beckett ${ }^{1 *}$, Patrice R. Jones ${ }^{2}$, Martin Veysey ${ }^{3}$ and Mark Lucock ${ }^{2}$ \\ ${ }^{1}$ School of Medicine \& Public Health, University of Newcastle, Australia; \\ ${ }^{2}$ School of Environmental \& Life Sciences, University of Newcastle, Australia; ${ }^{3}$ Hull York Medical School, UK
}

\begin{abstract}
Diet is an important modifiable determinant of disease, and it is becoming clear that diet and genetic risk factors are interactive in determining risk for diseases such as cardiovascular disease, diabetes and cancers. Advances in technology have improved our understanding of gene-nutrient interactions, and lead to the development of nutrigenetics, personalized nutrition based on genetics. While evidence is strong for some associations, others remain unclear. As such, the implementation of nutrigenetics remains controversial. While some argue it is not ready for clinical use, it has also been argued that nutrigenetics is unfairly held to a higher standard than traditional nutrition research. Despite the future promise of nutrigenetic testing for improving health outcomes, several barriers in science, technology, acceptance and ethics exist to its implementation. Gene-nutrient associations have been identified in a number of lifestyle-associated diseases, and better understanding of these relationships may lead to improved health outcomes. However, the success of nutrigenetics is not only dependent on the strength of the science, but in consumer acceptance and uptake. This narrative review provides an overview of the current landscape for nutrigenetics in relation to key disease states, and addresses the potential barriers to implementation.
\end{abstract}

Introduction

Diet is an important lifestyle exposure and is the largest modifiable determinant of risk for non-communicable disease, including cardiovascular disease, diabetes and some cancers. Importantly, diet is an ongoing, essential and unavoidable exposure for all people throughout life. Worldwide, non-communicable diseases account for $43 \%$ of the burden of disease currently, and the World Health Organization predicts they will represent $60 \%$ of the disease burden and $73 \%$ of all deaths by $2020 .^{1}$ The number of people with diabetes worldwide rose to 422 million in $2014,{ }^{2}$ cardiovascular disease is the leading cause of death, ${ }^{3}$ and incidence of cancers related to dietary risk factors, such as colorectal and esophageal cancers, are also rising. ${ }^{4}$ Today, most of the world's population lives in a country where overweight and obesity kills more people than underweight. ${ }^{5}$ Diet is, therefore, considered as a primary prevention strategy to reduce the risk for chronic diseases. However, as highlighted by the "Rose prevention paradox", a lifestyle measure that reduces risk in an entire population may offer little benefit to

Keywords: Nutrigenetics; Personalized nutrition; Genetics; Nutrition.

Abbreviations: FTO, fat mass and obesity associated gene; GWAS, genome-wide association studies; TCF7L2, transcription factor 7-like 2 gene.

Received: August 01, 2017; Revised: October 23, 2017; Accepted: November 07, 2017

${ }^{*}$ Correspondence to: Emma Beckett, School of Medicine and Public Health, University of Newcastle, Chittaway Rd, Ourimbah, NSW 2258, Australia. Tel: (02) 4348 4158, E-mail: emma.beckett@newcastle.edu.au

How to cite this article: Beckett EL, Jones PR, Veysey M, Lucock M. Nutrigenetics-Personalized Nutrition in the Genetic Age. Exploratory Research and Hypothesis in Medicine 2017;2(4):109-116. doi: 10.14218/ERHM.2017.00027.

\section{the individual. ${ }^{6}$}

Current public health initiatives and nutritional guidelines, both on a global and national scale, are generic recommendations. These recommendations are based on population estimates of required intakes and the prevention of deficiency. ${ }^{7}$ However, it is well known that there is considerable variance in how individuals respond to the same nutritional stimuli, and this alters the outcomes in terms of benefits and risks. The broader concept of personalized nutrition is not new, and population guidelines recognize some of this variance in limited cases, with some recommendations tailored to age, sex, or conditions such as pregnancy. ${ }^{8}$ Ranges of recommended intake values also account for a portion of this biological variance, as do specific recommendations related to the diagnosis of particular conditions, such as allergies or chronic diseases such as diabetes, ${ }^{9}$ cardiovascular disease and cancers. ${ }^{10,11}$

However, population guidelines, even with stratification, may not meet the needs of all individuals equally in terms of optimizing health outcomes and reduction of disease risk. ${ }^{12,13}$ With improving technology and advances in our understanding of genetics, the concept of personalized nutrition via nutrigenetics has emerged, where dietary recommendations can take into account the variance between individuals by tailoring to each person's unique genetics. ${ }^{13-15}$ While personalized nutrition based on genetics has significant future promise, there are many challenges in translating scientific advances into successful strategies for managing dietary intake and diet-related health outcomes on a large scale. These issues include the translation of reductionist research outcomes into practice, public perception and the likelihood of uptake, issues of privacy and ethics, commercialization, and the level of evidence required before the transition from traditional approaches is beneficial. It is important to consider if these challenges can be met 
and whether personalized nutrition can produce improved health outcomes and socioeconomic benefits relative to conventional generic dietary advice.

\section{Gene-nutrient interactions}

Dietary factors can interact with the genome in a number of ways. Firstly, genetic variance can influence nutritional status by modulating nutrient intake, uptake and metabolism. This is referred to as nutrigenetics. ${ }^{16}$ Furthermore, nutrients can regulate gene expression in a number of ways. Some nutrients can directly regulate gene expression via the interaction of stimulated receptors with response elements in the genome, acting as nuclear transcription factors. This direct interaction is referred to as nutrigenomics. ${ }^{16}$ Nutrients can also modify gene expression indirectly, via modulation of gene regulatory factors such as epigenetic marks, including the involvement of DNA methylation and miRNA. ${ }^{17}$ Importantly, nutrigenetics can impact upon the nutrigenomic and epigenetic responses and the sum of these events can modify disease risk. ${ }^{18}$

With improving technology, and completion of ground-breaking research, such as the human genome project, we are learning more about gene-nutrient interactions. This has led to a dramatic increase in research in this area. However, there are significant challenges to the translation of genetic data into personalized dietary advice, and it is questionable as to whether our level of understanding is sufficient for personalized nutrigenetics to progress. The majority of the published data on gene-nutrient interactions stem from observational studies and as such cannot definitively demonstrate cause and effect, and results can often be conflicting. Purpose-specific dietary intervention studies conducted by genotype are needed to achieve this. However, these are complex and expensive, and there are difficulties in considering multiple polymorphisms. Numerous genetic variants that influence nutrient metabolism have been identified, but it can be difficult to conclusively link single variants to the risk for multifactorial diseases, due to interactive and additive effects of multiple variants in defining nutrient metabolism and health outcomes. There is a need for quantitative assessment and mathematical modelling of multiple genetic effects.

Ultimately, the most important question is whether nutrigenetics can deliver results superior to population recommendations. It has been argued that the evidence for nutrigenetics is still too immature to be used in practice. ${ }^{19,20}$ However, it has also been argued that nutrigenetics is often held to a higher standard of evidence than generic nutritional advice, ${ }^{21,22}$ resulting in high-quality evidence for several gene-diet interactions potentially being ignored. Given the complexity of gene-nutrient interactions, and the known variance in nutrition-related health outcomes, regardless of genetics, we need to consider if we have set this standard too high. Nutrition is complex and outcomes difficult to assess, with or without a genetic component. It is, therefore, necessary to consider personalized nutrition in the same context as generic nutrition recommendations and not in the same context as clinical genetics. ${ }^{23}$

Nutrigenetic research often takes a reductionist approach to gene-nutrient interactions, examining the interactions between single polymorphisms and individual disease biomarkers, and how they are modified by single nutrients or food components. ${ }^{23,24}$ Each individual possesses potentially hundreds of gene variants that may have nutrigenetic consequences, and each consumes their own unique complex and varied diet. Complex statistical and bioinformatics modelling is required to integrate information on numerous genes, biomarkers, nutrients and foods for nutrigenetics to deliver on its promise of improving health outcomes.
An early application of nutrigenetics has been the diagnosis of conditions caused by single polymorphisms, such as genetic lactose intolerance and phenylketonuria. ${ }^{25}$ In many cases, genetic testing is not required for monogenic conditions, as the phenotype is sufficient basis for deciding on the appropriate dietary intervention. However, for complex polygenic traits, such as cardiovascular disease or diabetes, it is much more challenging to find evidence for the involvement of genes in disease development. These conditions have genetic risk factors, dietary risk factors, and these risks are modified by the interaction between the two and other lifestyle factors. ${ }^{26,27}$ As such, it is difficult to elucidate the involvement and modifiable component of the interactive factors, and a medical model of nutrigenetics, held to a clinical genetics level of evidence, may not be appropriate.

\section{Cardiovascular disease}

Cardiovascular disease has both genetic and dietary risk factors, and risk is likely modified by the interactions between the two. ${ }^{28}$ The predictive value of single polymorphisms may be small relative to known risk factors, such as family history of cardiovascular disease. ${ }^{29}$ Multiple minor genetic differences could be modulated by multiple dietary factors, resulting in multiple minor changes in gene expression. Depending on the interactions, these variables could result in negligible changes in final phenotype and therefore disease risk; however, they could also accumulate to significantly alter phenotype and outcomes. We do not yet have enough evidence to elucidate the mechanisms and outcomes of these complex interactions, and it is likely that additional interactions remain undiscovered. ${ }^{30}$ In the future, advances in this understanding may be supported by increased research investment in whole genome sequencing and bioinformatics initiatives, as well as improving technology and reducing associated testing costs.

Homocysteine is accepted as an independent risk factor for cardiovascular disease, ${ }^{31}$ with homocysteine levels being inversely associated with folate levels. It has been established that the MTH$F R$-677T allele results in the enzyme methylenetetrahydrofolate reductase having reduced activity $(\sim 35 \%$ of the MTHFR- $677 \mathrm{C}$ variant) ${ }^{32}$ Low folate status, therefore, impacts homocysteine levels more severely in individuals with the MTHFR-677TT genotype, and the standard recommendations for folate intake have been shown to be insufficient to maintain homocysteine levels below the risk level in this population. It is accepted that increasing folate intake (from $200 \mu \mathrm{g} /$ day to $400-600 \mu \mathrm{g} /$ day) reduces the risk for hyperhomocysteinemia in most MTHFR-677TT individuals. There is no reliable evidence that these levels cause harm, and they remain below the upper intake limits found in generic advice. ${ }^{33}$ As such, this is an example of where personalized recommendations may result in improved outcomes. However, this could also support the increase in population-wide intakes, as homocysteine levels are reduced in populations exposed to folic acid fortification programs. ${ }^{34-37}$

The response of plasma low-density lipoprotein and triacylglycerols (triglycerides) to supplementation with fish oil are clear examples of individual variability in response to an intervention resulting from the influence of both genetic and environmental factors. In a study of fish oil supplementation in 55 males, the mean change in plasma triacylglycerol was a $35 \%$ reduction. However, the variance of individual changes ranged from a $114 \%$ reduction to an $88 \%$ increase, demonstrating that the statistically significant reduction in the mean did not result in an improved outcome for all individuals. Similarly, the mean change for plasma low-density lipoprotein was a $7 \%$ increase, but with the variance of change 
ranging from a $61 \%$ increase to a $50 \%$ reduction. ${ }^{38,39}$ In the same cohort, ${ }^{38}$ and independently, ${ }^{40}$ it was determined that the APOE2 genotype was related to the magnitude of response, and this response may also be related to sex. ${ }^{41}$

Together these data suggest that while fish oil supplementation may improve cardiovascular biomarkers for a subset of individuals this is not true for all, and in some cases, it may actually be detrimental. As such, this may be an example of where it is not appropriate to produce population-based recommendations, whether they are public health guidelines, or used for the marketing of supplements. However, there is a lack of evidence to link the variance in responses to genotype, ${ }^{42}$ and further prospective studies including genotyping are needed to understand how personalized recommendations could be used to overcome the variance in responses and to assess whether this ultimately impacts disease risk, as these interactions remain poorly understood.

\section{Diabetes}

It is known that type 2 diabetes has both dietary and genetic risk factors and that outcomes are dependent on the combined and/or interactive influence of these, and other lifestyle risk factors. ${ }^{43-45}$ The majority of genes implemented in the progression of type 2 diabetes relate to pathways influencing fat distribution and insulin sensitivity. Genetic risk scores for type 2 diabetes are robust predictors of disease and have been shown to interact with western diets (high fat and sugar) to further predict outcomes. ${ }^{46}$

Genome-wide association studies (GWAS) have identified nearly 100 gene variants associated with modified risk for type 2 diabetes ${ }^{47}$ with a recent review suggesting 27 of these interact with diet to modify progression of type 2 diabetes. ${ }^{48}$ Notably, the transcription factor 7-like 2 gene (TCF7L2), involved in Wnt signaling, has the strongest influence on risk for type 2 diabetes. Common variants in this gene have been shown to interact with high intake of both carbohydrate and fiber to modify risk for type 2 diabetes. ${ }^{49,50}$ Due to the direct association between obesity and type 2 diabetes risk, a number of gene-diet interactions modifying risk of obesity have been identified that are of relevance to type 2 diabetes. Examples include the interactions between genotypes for the fat mass and obesity associated gene $($ FTO $),{ }^{51}$ PPARG,${ }^{52,53}$ $P L I N,{ }^{54}$ and $M C 4 R$ and diet, ${ }^{55}$ which influence disease-related outcomes, such as insulin sensitivity.

GWAS has also identified more than 40 independent polymorphisms associated with type 1 diabetes; however, the loci identified do not fully explain the heritability component estimated from familial studies, ${ }^{56}$ suggesting that dietary and other lifestyle factors are also involved in pathogenesis. Additional studies are needed to fully elucidate the role of gene-nutrient interactions in the etiology of diabetes.

\section{Cancer}

A plethora of genes have been linked to cancer risk and outcomes. However, few associations between gene variants and cancer risk remain robust, or reproducible, likely due to the interactive influence of diet and other environmental factors in epidemiological studies. ${ }^{57}$ Genome instability is a hallmark feature of cancers, with hundreds of genes involved in maintaining genome integrity. ${ }^{58}$ The interactions between these genes and diet indicate potential mechanisms by which personalized nutrition may influence cancer outcomes. $^{59}$
Gene variants involved in gene-diet interactions in cancer are namely those involved in detoxifying carcinogens and repairing DNA damage. The majority of these are specific to colorectal cancer, which has clear links to dietary risk factors. ${ }^{60,61}$ Increased risk of colorectal cancer has been shown with high red meat consumption in combination with variants in CYP2E1, CYP1B1, SULT1A1 and other members of the cytochrome P450 family of detoxifying genes. ${ }^{62-64}$ Several other gene variants have also been implicated in gene-diet interactions that have been shown to decrease colorectal cancer risk. Notably, common variants in the vitamin D receptor gene and MTHFR which codes for an important enzyme in folate metabolism; both have been shown to decrease risk of colorectal cancer when combined with diets high in calcium/vitamin D and folate respectively. ${ }^{65-67}$ Whilst the majority of reported gene-diet interactions are specific to colorectal cancers, gene-diet interactions have also been reported in progression of gastrointestinal, stomach, breast, lung and prostate cancer. ${ }^{57}$

Another well-studied gene-nutrient interaction involves cruciferous vegetables, which have been linked by systematic review with reduced lung cancer in individuals with polymorphisms in the GSTT1 and GSTM1 genes, which code for glutathione s-transferases, but not in individuals without these variants. ${ }^{68,69}$ However, it is unclear how clinically relevant these findings will prove to be, as the standard public health message to eat less meat and more vegetables applies regardless of genotype and is likely to be involved in the reduction of risk of multiple diseases. The benefit of these findings, however, may be found in the development of nutraceuticals for intervention in genetically at-risk individuals, should a mechanism for this interaction be identified. Interactions have also been shown between genes and diet in measures of DNA damage, ${ }^{70}$ prostate cancer risk and levels of the glutathione s-transferase alpha. ${ }^{71,72}$

\section{Cognitive decline}

APOE has been identified as a susceptibility gene for Alzheimer's disease, with the e 4 variant increasing risk for disease. The Risk Evaluation and Education for Alzheimer's Disease (commonly known as REVEAL) study examined how knowing $A P O E$ e4 status impacted behavior change in the adult offspring of parents with Alzheimer's disease. ${ }^{73}$ Having a parent who suffered from the disease, all study participants showed a higher-than-average risk for Alzheimer's disease, regardless of genotype; however, those carrying the $A P O E$ e4 variant were at higher risk. Participants were given a numerical estimate of their risk and were then randomly allocated into groups. Controls were not given any genotypic data, and the intervention groups were genotyped for $A P O E$ e 4 and their status revealed to them. Participants who were APOE e4-positive had a higher overall numerical risk score. ${ }^{73,74}$ One year later, similar proportions of positive behavior changes were reported among controls and among participants who were told that they were APOE e4-negative; however, additional positive behavior changes were reported approximately twice as often among participants who were told that they had the $A P O E$ e 4 risk variant. ${ }^{73}$

\section{Obesity}

Obesity is related to both dietary and genetic variables, and again the interaction between the two are likely to be important in determining phenotype, both in terms of risk for obesity and risk for diseases where obesity is a known risk factor. ${ }^{75}$ GWAS has revealed 
that body fat patterns have large genetic components, with 97 loci related to fat accumulation and an additional 49 loci relating to body fat distribution. ${ }^{76,77}$ Implicated genes in these loci have diverse roles and are involved in pathways such as those regulating satiety, food intake, energy metabolism and adipogenesis. ${ }^{76}$ Monozygotic (i.e. identical) twins have strong similarities in the adaptation to long-term overfeeding and in terms of weight gain and fat distribution, ${ }^{78}$ demonstrating genetic concordance.

Insight into genes that influence obesity has led to the calculation of genetic risk scores, the sum of obesity risk conferred by multiple gene variants. Diet (particularly fat and energy intake) has been shown to interact with genetic risk scores to alter the obesity risk..$^{79}$ Genes implemented in diet-gene interactions in obesity namely include FTO, MC4R, APOA2, PLIN and PPARG genes. $F T O$ is regarded as the first identified obesity gene. Common genetic variance in FTO is strongly associated with increases in body mass index, with this association shown to be enhanced by diets high in dietary fat and protein. ${ }^{80,81}$ Similar associations have been found for the $M C 4 R$ gene, involved in appetite regulation. ${ }^{82,83}$

Gene-diet interactions in obesity have also been shown between high saturated fat intake and $A P O A 2$, which codes for an apolipoprotein, ${ }^{84}$ and variants in $P P A R G$, which codes for a nuclear transcription factor. ${ }^{52,85}$ Notably, a common polymorphism in PLIN, which is involved in the regulation of lipid storage in adipocytes, has been shown to decrease risk of obesity when combined with a high carbohydrate intake, but increases obesity risk when combined with a low intake of this macronutrient. ${ }^{86}$ These data demonstrate the difficulty in the "one-size fits all" approach to weight management, and in particular, weight loss.

In a study conducted on patients with a history of weight loss failures, it was found that nutrigenetic screening resulted in increased compliance and longer-term body mass index reductions, when compared with standard weight-loss advice. ${ }^{87}$ However, it was also shown that the high-risk individuals had lower perceived behavioral control over their eating and hence felt less able to change their dietary habits. ${ }^{88}$ Another study found that genetic testing increased self-confidence in the participant's ability to lose weight, regardless of the actual result. ${ }^{89}$

\section{Consumer acceptance}

The utilization and advancement of nutrigenetics, and personalized nutrition more broadly, is not just dependent on the strength of the data, elucidating mechanisms and defining the appropriate level of evidence required for implementation but requires public acceptance to facilitate uptake. Motivating individuals to change dietary behaviors is one of the biggest challenges for any nutritional intervention..$^{90}$ There must be ease of use and access, and a perception of benefit. Genetic testing, in general, has a unique set of barriers to uptake, and several of these remain in the context of nutrigenetics, regardless of outcomes.

Numerous studies have been conducted into the acceptance of genetic testing in general..$^{91-95}$ Whilst testing is well accepted and becoming routine in the cases of high penetrance single polymorphisms, such as the $B R C A 1$ gene in breast cancer risk, in nutrigenetics, however, the associations are often weaker and less clear. ${ }^{92,95}$ Although, attitudes vary by demographics and results have been mixed. It has been reported that men are more willing to undergo genetic testing, ${ }^{96,97}$ but the opposite association has also been reported. ${ }^{98}$ It has also reported that age is a factor in acceptance of genetic testing; yet, some studies have found that older people are more willing, ${ }^{97,98}$ while others have reported that younger adults are the most likely to take part. ${ }^{96}$

Health has been identified as a primary motivator for undergoing genetic testing, ${ }^{96,98}$ which may facilitate the uptake of nutrigenetics, given that diet is a major modifiable determinant of disease. Acceptance may also be linked to current health; for example, respondents with high blood cholesterol or central adiposity were more likely to identify as willing than those without to undergo genetic testing, in general, and specifically for dietary modification. ${ }^{98}$ However, several possible outcomes to this are possible. Joost et al. ${ }^{99}$ suggested that individuals identified as having a higher disease risk through genetic testing may be more motivated to comply with a dietary intervention; however, it was also noted that knowledge of a genetic predisposition may result in a fatalistic attitude and reduced compliance. Furthermore, Hunter et al. ${ }^{100}$ reasoned that a negative result may lead to reduced motivation as individuals become reassured that they will not develop disease. Communicating the nuanced nature of risk and risk modification through nutrigenetics will be vital to ensure responses to information are not detrimental to outcomes.

Interestingly, in a study of familial hypercholesterolemia, participants with the at-risk polymorphisms were less likely to believe that eating a lower fat diet would reduce their cholesterol levels, and more likely to believe that medication would. ${ }^{101}$ Acceptance of genetic testing and personalized nutrition may not depend on the actual science but on the consumers' understanding of its implications for their personal health. However, following a systematic review, Marteau et al. ${ }^{101}$ argued in addition to significant gaps in the relevant science, there is limited evidence that nutrigenetic dietary advice will motivate appropriate behavior changes.

\section{Technology and regulation}

Web-based and smartphone technologies increase product reach and ease of delivery, but also raise issues of data security and accuracy of information. However, the technology for offering directto-consumer genetic testing has out-paced regulation for its provision, at times out-pacing the scientific evidence. Therefore, there needs to be a progression of regulation and technology to ensure consumer privacy is protected, data is appropriately stored, and that consumers are not misled. Early practitioners of nutrigenetics need to be mindful that inaccurate information offered prematurely can damage the reputation of the field. This may be exacerbated by the delivery of genetic information outside of a clinical setting.

Several studies have documented concerns regarding the technology used to provide nutrigenetic information. These include online privacy concerns, and the potential for information to be misused by insurers, employers, governments or other entities for profit or exploitation. ${ }^{102-104}$ Advances in technology have driven the rise of personalized nutrition in general and nutrigenetics specifically. This includes the advances in genetic testing technology and the reduction in cost, as well as the use of technology for the collection and dissemination of information. The expansion of internet delivery systems needs to be considered in personalized nutrition. As oversight and regulation varies by jurisdiction, it is reasonable for consumers to be cautious about their privacy and future use of their data. Additionally, provision of results directly to the consumer may be harmful without the input of a genetic counselor. ${ }^{105}$

\section{Ethical considerations for implementation}

There is significant debate surrounding whether or not the current 
knowledge base is sufficient for ethically responsible implementation of nutrigenetic testing. ${ }^{23,25,106,107}$ While there is still much to be discovered, we need to consider if we are holding nutrigenetics to a higher standard than generic population recommendations. ${ }^{23}$ The ethics of implementation may need to be considered on a case-bycase basis. For some gene-nutrient interactions, there is significant evidence that for some individuals with particular genotypes there could be a benefit from following dietary patterns other than those recommended by the standard guidelines; however the strength of evidence varies depending on the association in question. The key question is how to proceed in the face of uncertainty. Gorman et $a l .^{23}$ argue that a precautionary approach should be adopted, suggesting that personalized dietary advice should be offered only in cases where there is strong scientific evidence for health benefits, followed by continued stepwise evaluation to identify unforeseen behavioral and psychological effects. ${ }^{23}$

\section{Future research predictions}

The use of genotypic information in personalized nutrition offers considerable future promise, but significant barriers exist to successful implementation, independent of scientific knowledge. These include consumer acceptance, ethical, technological and regulatory considerations. Research into nutrigenetics has produced inconsistent results; however, the same could be said for conventional nutrition studies. This is not necessarily due to the overall quality of the research and the magnitude of the body of knowledge, rather it is due to the complexity interactions between nutrition, genetics, and long-term health. Improved frameworks are required to translate nutrigenetic studies into usable guidelines to direct practicing nutrition and medical professionals. This will require an interdisciplinary approach, including geneticists, bioinformaticians, nutritionists, dietitians and other biomedical professionals. ${ }^{108}$

Furthermore, additional research is needed not only into the gene-nutrient interactions themselves but also into the public attitudes and acceptance on nutrigenetics and the associated risks and benefits of uptake. Without a holistic approach to implementation, it is unlikely that nutrigenetics will deliver on its early promise to improve health outcomes.

\section{Conclusions}

The ongoing reduction in costs of genetic testing, and the improved technology available to collect and disseminate information will lead to ongoing improvements in both quality and quantity of relevant data. There is significant evidence of gene-nutrient interactions in a number of chronic conditions, such as cardiovascular disease, diabetes and obesity, and nutrigenetics could lead to improved outcomes for patients and consumers. However, implementation of nutrigenetic testing in the mainstream will depend on numerous factors, including regulation, technology and consumer acceptance, and not just availability of scientific evidence. It is also necessary for the public and implementing authorities to decide what level of evidence is required before nutrigenetics is no longer considered to be controversial.

\section{Acknowledgments}

Emma Beckett is supported by an NHMRC Early Career Fellowship (APP1129430). Patrice Jones is supported by a Research
Training Program (RTP) Scholarship from the Australian Government.

\section{Conflict of interest}

The authors have no conflict of interests related to this publication.

\section{Author contributions}

Manuscript writing (EB, PJ), design and revision (ML, MV).

\section{References}

[1] WHO NCD Surveillence. [Accessed July 2017]. Available from: http:// www.who.int/ncd_surveillance/strategy/en.

[2] Mathers CD, Loncar D. Projections of Global Mortality and Burden of Disease from 2002 to 2030. PLoS Med 2006;3(11):e442. doi:10.1371/ journal.pmed.0030442.

[3] Roth GA, Huffman MD, Moran AE, Feigin V, Mensah GA, Naghavi M, et al. Global and regional patterns in cardiovascular mortality from 1990 to 2013. Circulation 2015;132(17):1667-1678. doi:10.1161/ CIRCULATIONAHA.114.008720.

[4] Key TJ, Schatzkin A, Willett WC, Allen NE, Spencer EA, Travis RC. Diet, nutrition and the prevention of cancer. Public Health Nutr 2004;7(1A):187-200. doi:10.1079/PHN2003588.

[5] WHO factsheet - Obesity and Overweight. [Accessed July 2017]. Availble from: http://www.who.int/mediacentre/factsheets/fs311/ en/.

[6] Thompson C. Rose's prevention paradox. J Appl Philos 2016. doi:10.1111/japp.12177.

[7] WHO Dietary recommendations/Nutritional requirements. [Accessed July, 2017]. Available from: http://www.who.int/nutrition/ topics/nutrecomm/en/.

[8] Nutrient Reference Values. [Accessed July, 2017]. Available from: https://www.nrv.gov.au/.

[9] Jannasch F, Kröger J, Schulze MB. Dietary patterns and type 2 diabetes: a systematic literature review and meta-analysis of prospective studies. J Nutr 2017;147(6):1174-1182. doi:10.3945/jn.116.242552.

[10] Eilat-Adar S, Sinai T, Yosefy C, Henkin Y. Nutritional Recommendations for Cardiovascular Disease Prevention. Nutrients 2013;5(9):36463683. doi:10.3390/nu5093646.

[11] PDQ Supportive and Palliative Care Editorial Board. Nutrition in Cancer Care $\left(\mathrm{PDQ}^{\circledR}\right)$ : Health Professional Version. Bethesda (MD): National Cancer Institute (US); 2002. 2017 Nov 17.

[12] Betts JA, Gonzalez JT. Personalised nutrition: What makes you so special? Nutrition Bulletin 2016;41(4):353-359. doi:10.1111/nbu.12238.

[13] Fenech M, El-Sohemy A, Cahill L, Ferguson LR, French TA, Tai ES, et al. Nutrigenetics and nutrigenomics: viewpoints on the current status and applications in nutrition research and practice. J Nutrigenet Nutrigenomics 2011;4(2):69-89. doi:10.1159/000327772.

[14] de Roos B. Personalised nutrition: ready for practice? Proc Nutr Soc 2013;72(1):48-52. doi:10.1017/S0029665112002844.

[15] Hesketh J. Personalised nutrition: how far has nutrigenomics progressed? Eur J Clin Nutr 2013;67(5):430-435. doi:10.1038/ ejcn.2012.145.

[16] Kang JX. The coming of age of nutrigenetics and nutrigenomics. J Nutrigenet Nutrigenomics 2012;5(1):I-II. doi:10.1159/000339375.

[17] Beckett EL, Yates Z, Veysey M, Duesing K, Lucock M. The role of vitamins and minerals in modulating the expression of microRNA. Nutr Res Rev 2014;27(1):94-106. doi:10.1017/S0954422414000043.

[18] Friso S, Choi SW. Gene-nutrient interactions and DNA methylation. J Nutr 2002;132(8 Suppl):2382s-2387s.

[19] Camp KM, Trujillo E. Position of the Academy of Nutrition and Dietetics: nutritional genomics. J Acad Nutr Diet 2014;114(2):299-312. doi:10.1016/j.jand.2013.12.001. 
[20] Cominetti C, Horst MA, Rogero MM. Brazilian Society for Food and Nutrition position statement: nutrigenetic tests. Nutrire 2017;42(1):10. doi:10.1186/s41110-017-0033-2.

[21] Wood PA. Potential of nutrigenetics in the treatment of metabolic disorders. Expert Rev Endocrinol Metab 2008;3(6):705-713. doi:10.1586/17446651.3.6.705.

[22] Haga SB, Khoury MJ, Burke W. Genomic profiling to promote a healthy lifestyle: not ready for prime time. Nat Genet 2003;34(4):347-350. doi:10.1038/ng0803-347.

[23] Görman U, Mathers JC, Grimaldi KA, Ahlgren J, Nordström K. Do we know enough? A scientific and ethical analysis of the basis for genetic-based personalized nutrition. Genes Nutr 2013;8(4):373-381. doi:10.1007/s12263-013-0338-6.

[24] Rimbach G, Minihane AM. Nutrigenetics and personalized nutrition: how far have we progressed and are we likely to get there? Proc Nutr Soc 2009;68(2):162-172. doi:10.1017/S0029665109001116.

[25] Pavlidis C, Patrinos GP, Katsila T. Nutrigenomics: A controversy. Appl Transl Genom 2015;4:50-53. doi:10.1016/j.atg.2015.02.003.

[26] Mead MN. Nutrigenomics: the genome-food interface. Environ Health Perspect 2007;115(12):A582-A589.

[27] Gaboon NEA. Nutritional genomics and personalized diet. Egyptian Journal of Medical Human Genetics 2011;12(1):1-7. doi:10.1016/j. ejmhg.2011.02.001.

[28] Juma S, Imrhan V, Vijayagopal P, Prasad C. Prescribing personalized nutrition for cardiovascular health: are we ready? J Nutrigenet Nutrigenomics 2014;7(3):153-160. doi:10.1159/000370213.

[29] Kullo IJ, Cooper LT. Early identification of cardiovascular risk using genomics and proteomics. Nat Rev Cardiol 2010;7(6):309-317. doi:10.1038/nrcardio.2010.53.

[30] Phillips CM. Nutrigenetics and metabolic disease: current status and implications for personalised nutrition. Nutrients 2013;5(1):32-57. doi:10.3390/nu5010032.

[31] Wald DS, Wald NJ, Morris JK, Law M. Folic acid, homocysteine, and cardiovascular disease: judging causality in the face of inconclusive trial evidence. BMJ 2006;333(7578):1114-1147. doi:10.1136/ bmj.39000.486701.68.

[32] Homocysteine Lowering Trialists' Collaboration. Dose-dependent effects of folic acid on blood concentrations of homocysteine: a metaanalysis of the randomized trials. Am J Clin Nutr 2005;82(4):806-812.

[33] Nutrient reference values folate. [Accessed July, 2017]. Available from: https://www.nrv.gov.au/nutrients/folate.

[34] Beckett EL, Martin C, Boyd L, Porter T, King K, Niblett S, et al. Reduced plasma homocysteine levels in elderly Australians following mandatory folic acid fortification - A comparison of two cross-sectional cohorts. J Nutr Intermed Metab 2017;8:14-20. doi:10.1016/j. jnim.2017.04.001.

[35] Hickling S, Hung J, Knuiman M, Jamrozik K, McQuillan B, Beilby J, et al. Impact of voluntary folate fortification on plasma homocysteine and serum folate in Australia from 1995 to 2001: a population based cohort study. J Epidemiol Community Health 2005;59(5):371-376. doi:10.1136/jech.2004.027078.

[36] Jacques PF, Selhub J, Bostom AG, Wilson PW, Rosenberg IH. The effect of folic acid fortification on plasma folate and total homocysteine concentrations. N Engl J Med 1999;340(19):1449-1454. doi:10.1056/NEJM199905133401901.

[37] Abdollahi Z, Elmadfa I, Djazayery A, Golalipour MJ, Sadighi J, Salehi $\mathrm{F}$, et al. Efficacy of flour fortification with folic acid in women of childbearing age in Iran. Ann Nutr Metab 2011;58(3):188-196. doi:10.1159/000329726.

[38] Minihane AM, Khan S, Leigh-Firbank EC, Talmud P, Wright JW, Murphy $\mathrm{MC}$, et al. ApoE polymorphism and fish oil supplementation in subjects with an atherogenic lipoprotein phenotype. Arterioscler Thromb Vasc Biol 2000;20(8):1990-1997. doi:10.1161/01. ATV.20.8.1990.

[39] Minihane AM. Fatty acid-genotype interactions and cardiovascular risk. Prostaglandins Leukot Essent Fatty Acids 2010;82(4-6):259-264. doi:10.1016/j.plefa.2010.02.014

[40] Olano-Martin E, Anil E, Caslake MJ, Packard CJ, Bedford D, Stewart G, et al. Contribution of apolipoprotein E genotype and docosahexaenoic acid to the LDL-cholesterol response to fish oil. Atherosclerosis 2010;209(1):104-110. doi:10.1016/j.atherosclerosis.2009.08.024.
[41] Caslake MJ, Miles EA, Kofler BM, Lietz G, Curtis P, Armah CK, et al, Effect of sex and genotype on cardiovascular biomarker response to fish oils: the FINGEN Study. Am J Clin Nutr. 2008;88(3):618-629.

[42] Madden J, Williams CM, Calder PC, Lietz G, Miles EA, Cordell H, et al. The impact of common gene variants on the response of biomarkers of cardiovascular disease (CVD) risk to increased fish oil fatty acids intakes. Annu Rev Nutr 2011;31:203-234. doi:10.1146/annurev-nutr-010411-095239.

[43] Dedoussis GV, Kaliora AC, Panagiotakos DB. Genes, diet and type 2 diabetes mellitus: a review. Rev Diabet Stud 2007;4(1):13-24. doi:10.1900/RDS.2007.4.13.

[44] Zheng JS, Niu K, Jacobs S, Dashti H, Huang T. Nutritional biomarkers, gene-diet interaction, and risk factors for type 2 diabetes. J Diabetes Res 2016;2016:8610501. doi:10.1155/2016/8610501.

[45] Berná G, Oliveras-López MJ, Jurado-Ruíz E, Tejedo J, Bedoya F, Soria $B$, et al. Nutrigenetics and nutrigenomics insights into diabetes etiopathogenesis. Nutrients 2014;6(11):5338-5369. doi:10.3390/ nu6115338.

[46] Qi L, Cornelis MC, Zhang C, van Dam RM, Hu FB. Genetic predisposition, Western dietary pattern, and the risk of type 2 diabetes in men. Am J Clin Nutr 2009;89(5):1453-1458. doi:10.3945/ajcn.2008.27249.

[47] Stancakova A, Laakso M. Genetics of type 2 diabetes. In: Stettler C, Christ E, Diem P, editors. Endocrine development Vol 31, Novelties in Diabetes. Basel: Karger Publishers; 2016. p. 203-220.

[48] Ortega Á, Berná G, Rojas A, Martín F, Soria B. Gene-diet interactions in type 2 diabetes: the chicken and egg debate. Int J Mol Sci 2017;18(6):E1188. doi:10.3390/ijms18061188.

[49] Cornelis MC, Qi L, Kraft P, Hu FB. TCF7L2, dietary carbohydrate, and risk of type 2 diabetes in US women. Am J Clin Nutr 2009;89(4):12561262. doi:10.3945/ajcn.2008.27058.

[50] Hindy G, Sonestedt E, Ericson U, Jing XJ, Zhou Y, Hansson O, et al. Role of TCF7L2 risk variant and dietary fibre intake on incident type 2 diabetes. Diabetologia 2012;55(10):2646-2654. doi:10.1007/s00125012-2634-x.

[51] Zheng Y, Huang T, Zhang X, Rood J, Bray GA, Sacks FM, et al. Dietary fat modifies the effects of FTO genotype on changes in insulin sensitivity. J Nutr 2015;145(5):977-982. doi:10.3945/jn.115.210005.

[52] Lamri A, Abi Khalil C, Jaziri R, Velho G, Lantieri O, Vol S, et al. Dietary fat intake and polymorphisms at the PPARG locus modulate BMI and type 2 diabetes risk in the D.E.S.I.R. prospective study. Int J Obes (Lond) 2012;36(2):218-224. doi:10.1038/ijo.2011.91.

[53] Soriguer F, Morcillo S, Cardona F, Rojo-Martínez G, de la Cruz Almaráz M, Ruiz de Adana Mde L, et al. Pro12Ala polymorphism of the PPARG2 gene is associated with type 2 diabetes mellitus and peripheral insulin sensitivity in a population with a high intake of oleic acid. J Nutr 2006;136(9):2325-2330.

[54] Corella D, Qi L, Tai ES, Deurenberg-Yap M, Tan CE, Chew SK, et al. Perilipin gene variation determines higher susceptibility to insulin resistance in Asian women when consuming a high-saturated fat, low-carbohydrate diet. Diabetes Care 2006;29(6):1313-1319. doi:10.2337/ dc06-0045

[55] Chambers JC, Elliott P, Zabaneh D, Zhang W, Li Y, Froguel P, et al. Common genetic variation near MC4R is associated with waist circumference and insulin resistance. Nat Genet 2008;40(6):716-718. doi:10.1038/ng.156

[56] Zanda M, Onengut-Gumuscu S, Walker N, Shtir C, Gallo D, Wallace C, et al. A genome-wide assessment of the role of untagged copy number variants in type 1 diabetes. PLoS Genet 2014;10(5):e1004367. doi:10.1371/journal.pgen.1004367.

[57] Lee SA. Gene-diet interaction on cancer risk in epidemiological studies. J Prev Med Public Health 2009;42(6):360-370. doi:10.3961/ jpmph.2009.42.6.360.

[58] Hanahan D, Weinberg RA. Hallmarks of cancer: the next generation. Cell 2011;144(5):646-674. doi:10.1016/j.cell.2011.02.013.

[59] Fenech MF. Nutriomes and personalized nutrition for DNA damage prevention, telomere integrity maintenance and cancer growth control. Cancer Treat Res 2014;159:427-441. doi:10.1007/978-3-64238007-5_24.

[60] Hou TY, Davidson LA, Kim E, Fan YY, Fuentes NR, Triff K, et al. Nutrient-gene interaction in colon cancer, from the membrane to cellular physiology. Annu Rev Nutr 2016;36:543-570. doi:10.1146/annurev- 
nutr-071715-051039.

[61] Elsamanoudy AZ, Neamat-Allah MAM, Mohammad FAH, Hassanien $\mathrm{M}, \mathrm{Nada} \mathrm{HA}$. The role of nutrition related genes and nutrigenetics in understanding the pathogenesis of cancer. Journal of Microscopy and Ultrastructure 2016;4(3):115-122. doi:10.1016/j.jmau.2016.02.002.

[62] Le Marchand L, Donlon T, Seifried A, Wilkens LR. Red meat intake, CYP2E1 genetic polymorphisms, and colorectal cancer risk. Cancer Epidemiol Biomarkers Prev 2002;11(10 Pt 1):1019-1024.

[63] Cotterchio M, Boucher BA, Manno M, Gallinger S, Okey AB, Harper PA. Red meat intake, doneness, polymorphisms in genes that encode carcinogen-metabolizing enzymes and colorectal cancer risk. Cancer Epidemiol Biomarkers Prev 2008;17(11):3098-3107. doi:10.1158/1055-9965.EPI-08-0341.

[64] Küry S, Buecher B, Robiou-du-Pont S, Scoul C, Sébille V, Colman H, et al. Combinations of cytochrome $\mathrm{P} 450$ gene polymorphisms enhancing the risk for sporadic colorectal cancer related to red meat consumption. Cancer Epidemiol Biomarkers Prev 2007;16(7):14601467. doi:10.1158/1055-9965.EPI-07-0236.

[65] Sharp L, Little J. Polymorphisms in genes involved in folate metabolism and colorectal neoplasia: a HuGE review. Am J Epidemiol 2004;159(5):423-443. doi:10.1093/aje/kwh066.

[66] Slattery ML, Neuhausen SL, Hoffman M, Caan B, Curtin K, Ma KN, et al. Dietary calcium, vitamin D, VDR genotypes and colorectal cancer. Int J Cancer 2004;111(5):750-756. doi:10.1002/ijc.20330.

[67] Takeshige N, Yin G, Ohnaka K, Kono S, Ueki T, Tanaka M, et al. Associations between vitamin $\mathrm{D}$ receptor (VDR) gene polymorphisms and colorectal cancer risk and effect modifications of dietary calcium and vitamin D in a Japanese population. Asian Pac J Cancer Prev 2015;16(5):2019-2026. doi:10.7314/APJCP.2015.16.5.2019.

[68] Brennan P, Hsu CC, Moullan N, Szeszenia-Dabrowska N, Lissowska $\mathrm{J}$, Zaridze $\mathrm{D}$, et al. Effect of cruciferous vegetables on lung cancer in patients stratified by genetic status: a mendelian randomisation approach. Lancet 2005;366(9496):1558-1560. doi:10.1016/S01406736(05)67628-3.

[69] Lam TK, Gallicchio L, Lindsley K, Shiels M, Hammond E, Tao XG, et al. Cruciferous vegetable consumption and lung cancer risk: a systematic review. Cancer Epidemiol Biomarkers Prev 2009;18(1):184-195. doi:10.1158/1055-9965.EPI-08-0710.

[70] Palli D, Masala G, Peluso M, Gaspari L, Krogh V, Munnia A, et al. The effects of diet on DNA bulky adduct levels are strongly modified by GSTM1 genotype: a study on 634 subjects. Carcinogenesis 2004;25(4):577-584. doi:10.1093/carcin/bgh033.

[71] Steinbrecher A, Rohrmann S, Timofeeva M, Risch A, Jansen E, Linseisen J. Dietary glucosinolate intake, polymorphisms in selected biotransformation enzymes, and risk of prostate cancer. Cancer Epidemiol Biomarkers Prev 2010;19(1):135-143. doi:10.1158/1055-9965. EPI-09-0660.

[72] Lampe JW, Chen C, Li S, Prunty J, Grate MT, Meehan DE, et al. Modulation of human glutathione S-transferases by botanically defined vegetable diets. Cancer Epidemiol Biomarkers Prev 2000;9(8):787793.

[73] Chao S, Roberts JS, Marteau TM, Silliman R, Cupples LA, Green RC. Health behavior changes after genetic risk assessment for Alzheimer disease: the REVEAL study. Alzheimer Dis Assoc Disord 2008;22(1):94-97. doi:10.1097/WAD.0b013e31815a9dcc.

[74] Fanshawe TR, Prevost AT, Roberts JS, Green RC, Armstrong D, Marteau TM. Explaining Behavior change after genetic testing: the problem of collinearity between test results and risk estimates. Genet Test 2008;12(3):381-386. doi:10.1089/gte.2007.0103.

[75] Pérusse L, Bouchard C. Gene-diet interactions in obesity. Am J Clin Nutr 2000;72(5 Suppl):1285S-1290S.

[76] Locke AE, Kahali B, Berndt SI, Justice AE, Pers TH, Day FR, et al. Genetic studies of body mass index yield new insights for obesity biology. Nature 2015;518(7538):197-206. doi:10.1038/nature14177.

[77] Shungin D, Winkler TW, Croteau-Chonka DC, Ferreira T, Locke AE, Mägi $R$, et al. New genetic loci link adipose and insulin biology to body fat distribution. Nature 2015;518(7538):187-196. doi:10.1038/ nature14132.

[78] Bouchard C, Tremblay A, Després JP, Nadeau A, Lupien PJ, Thériault $\mathrm{G}$, et al. The response to long-term overfeeding in identical twins. N Engl J Med 1990;322(21):1477-1482. doi:10.1056/
NEJM199005243222101.

[79] Celis-Morales CA, Lyall DM, Gray SR, Steell L, Anderson J, Iliodromiti $\mathrm{S}$, et al. Dietary fat and total energy intake modifies the association of genetic profile risk score on obesity: evidence from 48170 UK Biobank participants. Int J Obes (Lond) 2017;41(12):1761-1768. doi:10.1038/ijo.2017.169.

[80] Livingstone KM, Celis-Morales C, Lara J, Ashor AW, Lovegrove JA, Martinez JA, et al. Associations between FTO genotype and total energy and macronutrient intake in adults: a systematic review and meta-analysis. Obes Rev 2015;16(8):666-678. doi:10.1111/obr.12290.

[81] Frayling TM, Timpson NJ, Weedon MN, Zeggini E, Freathy RM, Lindgren $\mathrm{CM}$, et al. A common variant in the FTO gene is associated with body mass index and predisposes to childhood and adult obesity. Science 2007;316(5826):889-894

[82] Huang T, Zheng Y, Hruby A, Williamson DA, Bray GA, Shen Y, et al. Dietary protein modifies the effect of the MC4R genotype on 2-year changes in appetite and food craving: the POUNDS lost trial. J Nutr 2017;147(3):439-444. doi:10.3945/jn.116.242958.

[83] Koochakpoor G, Daneshpour MS, Mirmiran P, Hosseini SA, Hosseini-Esfahani F, Sedaghatikhayat B, et al. The effect of interaction between Melanocortin-4 receptor polymorphism and dietary factors on the risk of metabolic syndrome. Nutr Metab (Lond) 2016;13:35. doi:10.1186/s12986-016-0092-z.

[84] Corella D, Peloso G, Arnett DK, Demissie S, Cupples LA, Tucker K, et al. APOA2, dietary fat, and body mass index: replication of a genediet interaction in 3 independent populations. Arch Intern Med 2009;169(20):1897-1906. doi:10.1001/archinternmed.2009.343.

[85] Garaulet M, Smith CE, Hernández-González T, Lee YC, Ordovás JM. PPARY Pro12Ala interacts with fat intake for obesity and weight loss in a behavioural treatment based on the Mediterranean diet. Mol Nutr Food Res 2011;55(12):1771-1779. doi:10.1002/mnfr.201100437.

[86] Smith CE, Tucker KL, Yiannakouris N, Garcia-Bailo B, Mattei J, Lai CQ, et al. Perilipin polymorphism interacts with dietary carbohydrates to modulate anthropometric traits in hispanics of caribbean origin. J Nutr 2008;138(10):1852-1858.

[87] Arkadianos I, Valdes AM, Marinos E, Florou A, Gill RD, Grimaldi KA. Improved weight management using genetic information to personalize a calorie controlled diet. Nutr J 2007;6:29. doi:10.1186/14752891-6-29.

[88] Frosch DL, Mello P, Lerman C. Behavioral consequences of testing for obesity risk. Cancer Epidemiol Biomarkers Prev 2005;14(6):14851489.

[89] Harvey-Berino J, Gold EC, West DS, Shuldiner AR, Walston J, Starling RD, et al. Does genetic testing for obesity influence confidence in the ability to lose weight? A pilot investigation. J Am Diet Assoc 2001;101(11):1351-1353. doi:10.1016/S0002-8223(01)00323-6.

[90] Ronteltap A, van Trijp JC, Renes RJ. Consumer acceptance of nutrigenomics-based personalized nutrition. Br J Nutr 2009;101(1):132144. doi:10.1017/S0007114508992552.

[91] Henneman L, Timmermans DR, Van Der Wal G. Public attitudes toward genetic testing: perceived benefits and objections. Genet Test 2006;10(2):139-145. doi:10.1089/gte.2006.10.139.

[92] Morin K. Knowledge and attitudes of Canadian consumers and health care professionals regarding nutritional genomics. OMICS 2009;13(1):37-41. doi:10.1089/omi.2008.0047.

[93] Sanderson SC, Wardle J, Jarvis MJ, Humphries SE. Public interest in genetic testing for susceptibility to heart disease and cancer: a population-based survey in the UK. Prev Med 2004;39(3):458-464. doi:10.1016/j.ypmed.2004.04.051.

[94] Toiviainen $\mathrm{H}$, Jallinoja $\mathrm{P}$, Aro AR, Hemminki E. Medical and lay attitudes towards genetic screening and testing in Finland. Eur J Hum Genet 2003;11(8):565-572. doi:10.1038/sj.ejhg.5201006.

[95] Weir M, Morin K, Ries N, Castle D. Canadian health care professionals' knowledge, attitudes and perceptions of nutritional genomics. $\mathrm{Br}$ J Nutr 2010;104(8):1112-1119. doi:10.1017/S0007114510002035.

[96] Cherkas LF, Harris JM, Levinson E, Spector TD, Prainsack B. A survey of UK public interest in internet-based personal genome testing. PLoS One 2010;5(10):e13473. doi:10.1371/journal.pone.0013473.

[97] Sanderson SC, Wardle J, Humphries SE. Public health genomics and genetic test evaluation: the challenge of conducting behavioural research on the utility of lifestyle-genetic tests. J Nutrigenet Nutrig- 
Explor Res Hypothesis Med

enomics 2008;1(5):224-231. doi:10.1159/000149826.

[98] Stewart-Knox BJ, Bunting BP, Gilpin S, Parr HJ, Pinhão S, Strain $\mathrm{JJ}$, et al. Attitudes toward genetic testing and personalized nutrition in a representative sample of European consumers. Br J Nutr 2009;101(7):982-989. doi:10.1017/S0007114508055657.

[99] Joost HG, Gibney MJ, Cashman KD, Görman U, Hesketh JE, Mueller $\mathrm{M}$, et al. Personalised nutrition: status and perspectives. Br J Nutr 2007;98(1):26-31. doi:10.1017/S0007114507685195.

[100] Hunter DJ, Khoury MJ, Drazen JM. Letting the genome out of the bottle-will we get our wish? N Engl J Med 2008;358(2):105-107. doi:10.1056/NEJMp0708162.

[101] Marteau T, Senior V, Humphries SE, Bobrow M, Cranston T, Crook $\mathrm{MA}$, et al. Psychological impact of genetic testing for familial hypercholesterolemia within a previously aware population: a randomized controlled trial. Am J Med Genet A 2004;128A(3):285-293. doi:10.1002/ajmg.a.30102.

[102] Nyrhinen T, Leino-Kilpi H, Hietala M. Ethical issues in the diagnostic genetic testing process. New Genet Soc 2004;23(1):73-87. doi:10.1 080/1463677042000189570.

[103] Bates BR, Lynch JA, Bevan JL, Condit CM. Warranted concerns, war-
Beckett E.L. et al: Nutrigenetics in personalized nutrition

ranted outlooks: a focus group study of public understandings of genetic research. Soc Sci Med 2005;60(2):331-344. doi:10.1016/j. socscimed.2004.05.012.

[104] Vayena E, Gourna E, Streuli J, Hafen E, Prainsack B. Experiences of early users of direct-to-consumer genomics in Switzerland: an exploratory study. Public Health Genomics 2012;15(6):352-362. doi:10.1159/000343792.

[105] Marietta C, McGuire AL. Direct-to-consumer genetic testing: is it the practice of medicine? J Law Med Ethics 2009;37(2):369-374. doi:10.1111/j.1748-720X.2009.00380.x.

[106] Hurlimann T, Menuz V, Graham J, Robitaille J, Vohl MC, Godard B. Risks of nutrigenomics and nutrigenetics? What the scientists say. Genes Nutr 2014;9(1):370. doi:10.1007/s12263-013-0370-6.

[107] Castle D, Ries NM. Ethical, legal and social issues in nutrigenomics: the challenges of regulating service delivery and building health professional capacity. Mutat Res 2007;622(1-2):138-143. doi:10.1016/j. mrfmmm.2007.03.017.

[108] Murgia C, Adamski MM. Translation of nutritional genomics into nutrition practice: the next step. Nutrients 2017;9(4):E366. doi:10.3390/nu9040366. 